\title{
RESUME PEMBUATAN PROGRAM APLIKASI BORLAND DELPHI 7.0 BERBASIS PAPERPLAIN
}

\author{
Nadya Karina Putri \\ 175100066 \\ Universitas Mitra Indonesia,Sistem Informasi \\ Nadyakarinaputri.student@umitra.ac.id
}

\begin{abstract}
Abstrak
Seiring perkembangan mobile/handphone aplikasi penghitung dapat digunakan untuk mempermudah proses perhitungan secara cepat dan mudah dalam kehidupan sehari-hari. Namun terkadang kita sering menemukan permasalahan yang berhubungan dengan perhitungan baik itu mendasar maupun konversi antar basis bilangan. Maka dari itu penulis berusaha menciptakan aplikasi penghitung dan konversi basis bilangan. Penulis menggunakan data primer dan data sekunder sebagai acuan dalam membuat aplikasi ini. Data primer diperoleh dengan cara mencari aplikasi sejenis sebagai referensi dalam membuat aplikasi sesuai dengan kebutuhan pengguna. Data sekunder diperoleh dari jurnal maupun literatur yang mendukung kelengkapan data primer. Aplikasi ini dibuat menggunakan aplikasi delphi 7.0.
\end{abstract}

\section{A. CAPTURE PROGRAM}

\section{PORTAL}

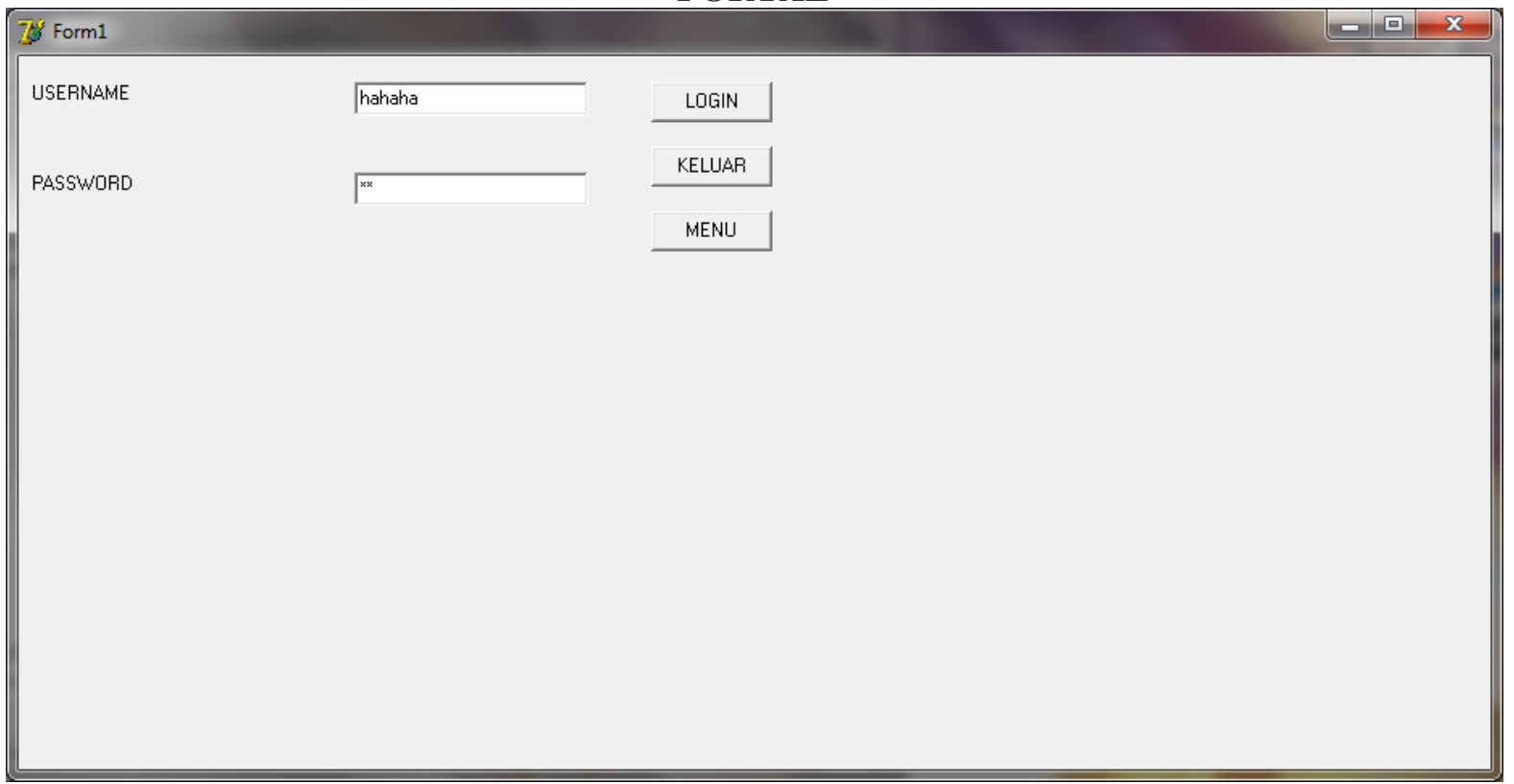




\section{KALKULATOR}

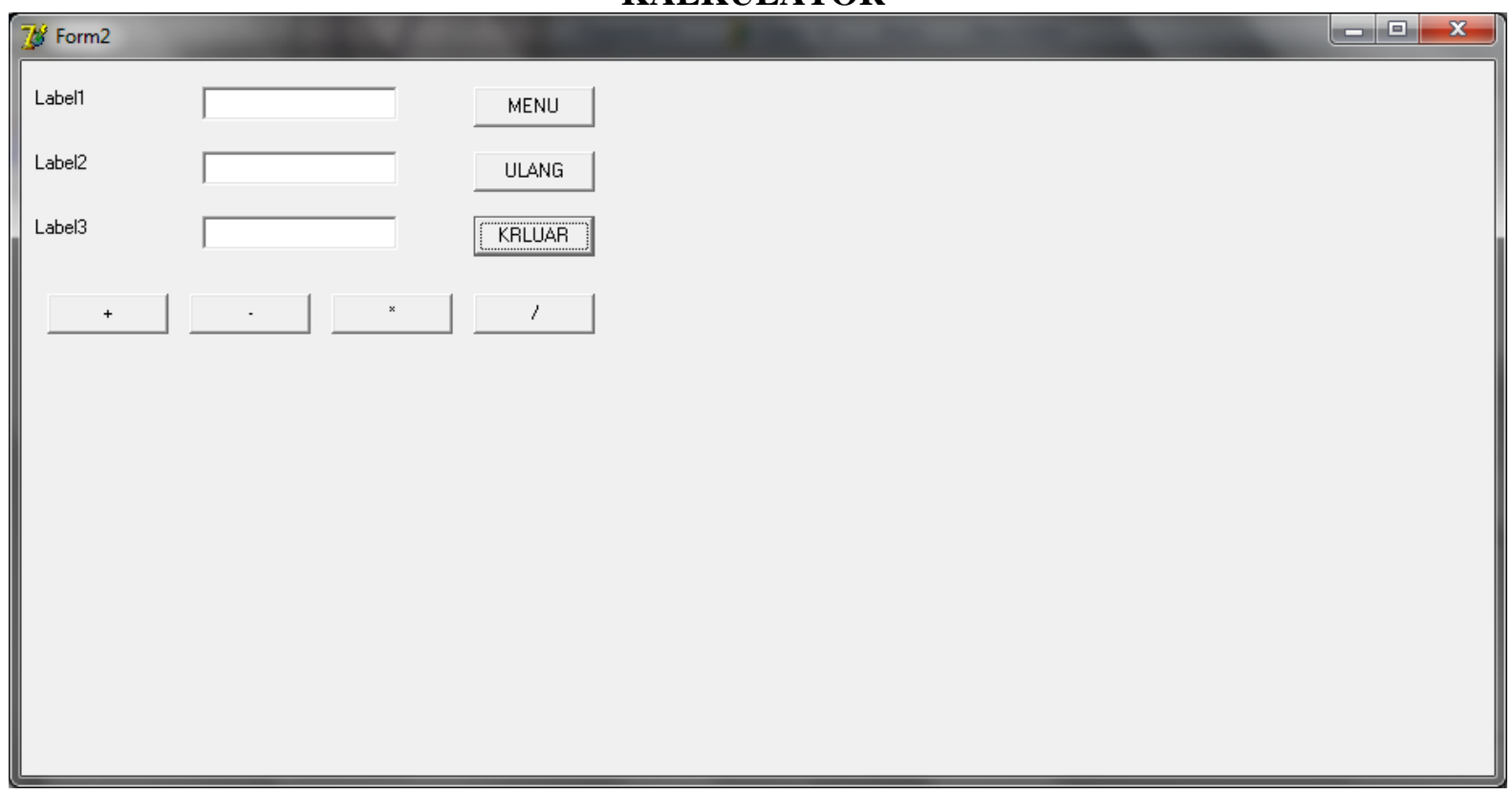

SEGITIGA

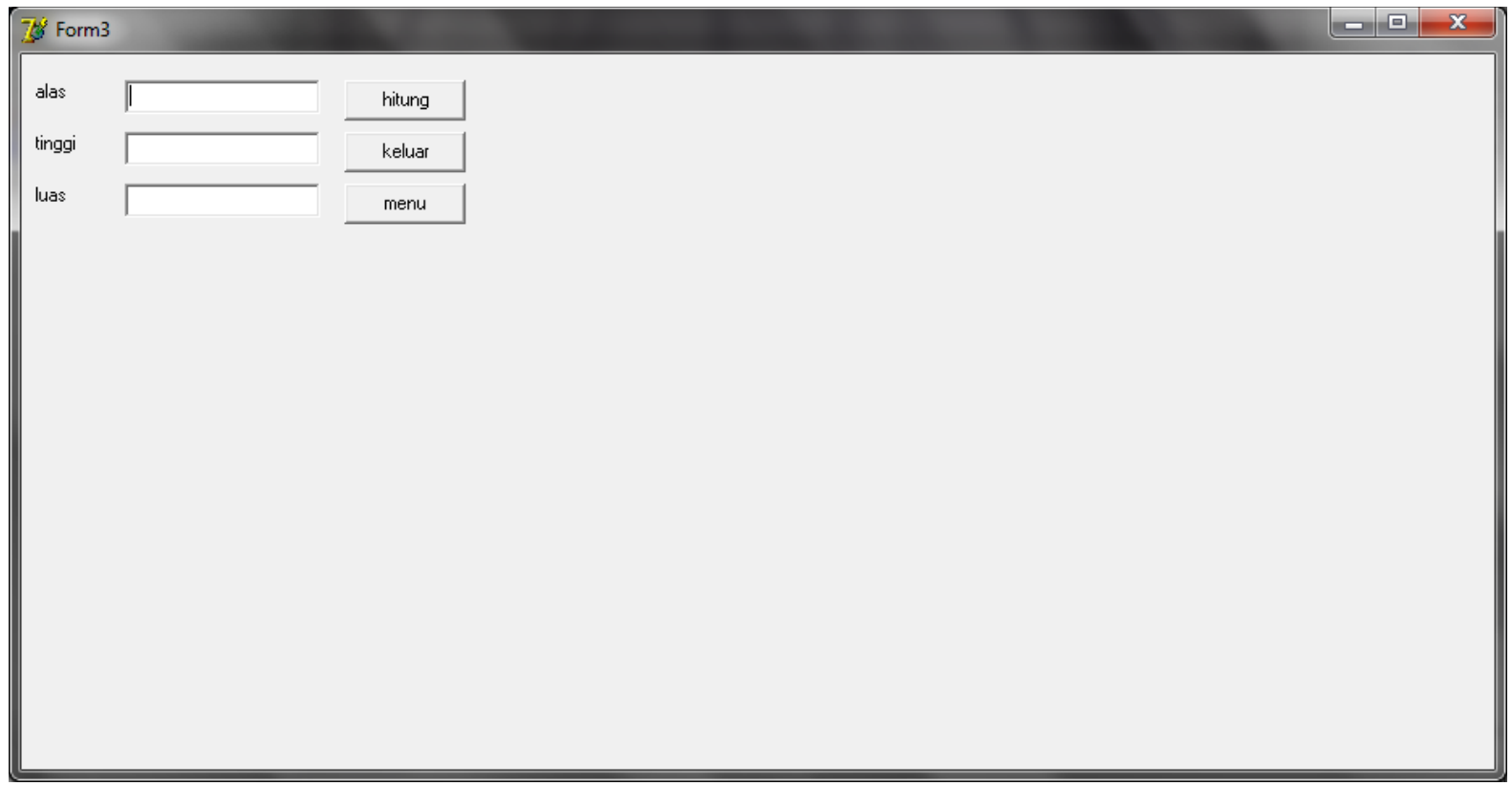




\section{DISKON}

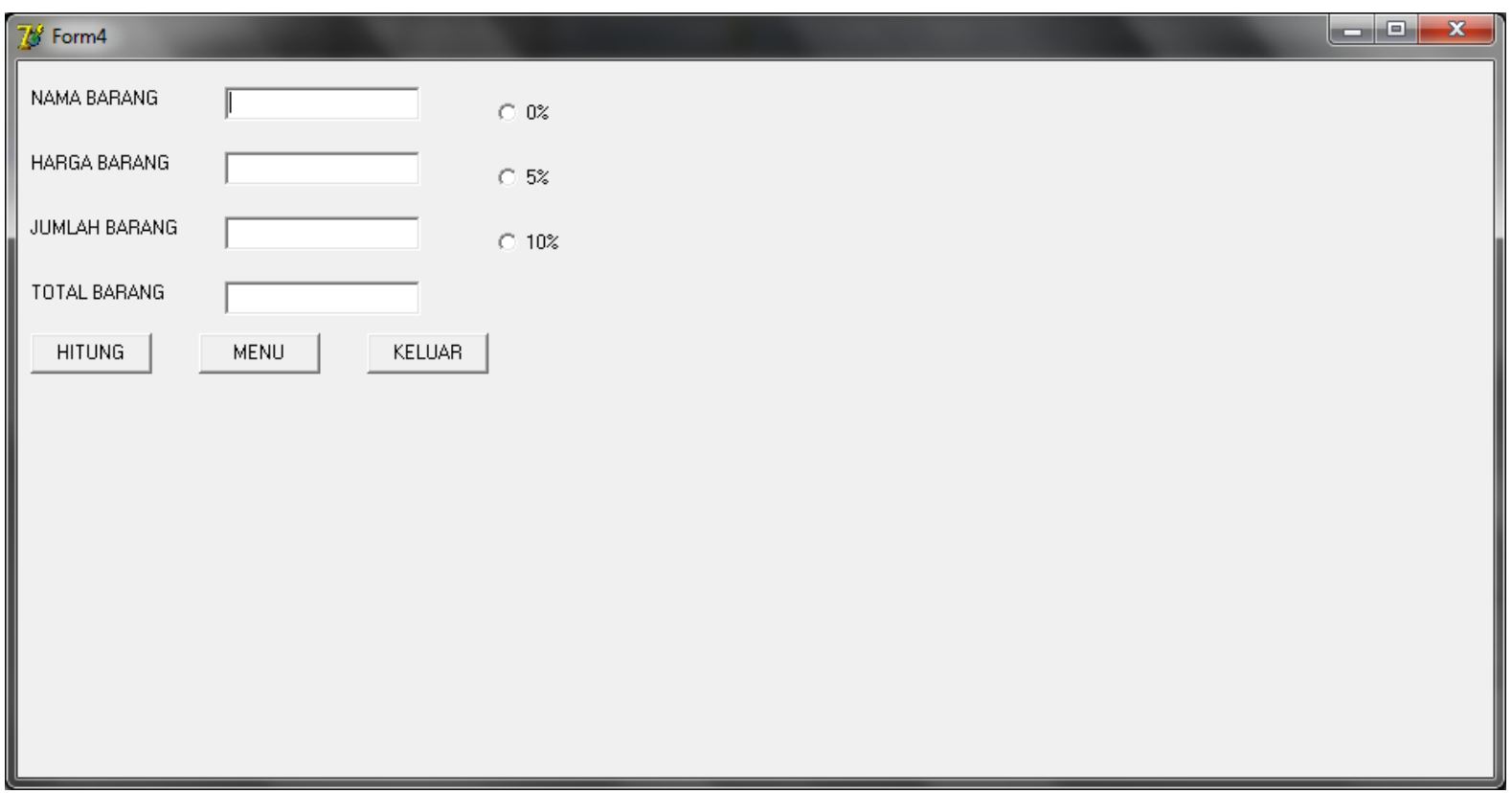

DATABASE

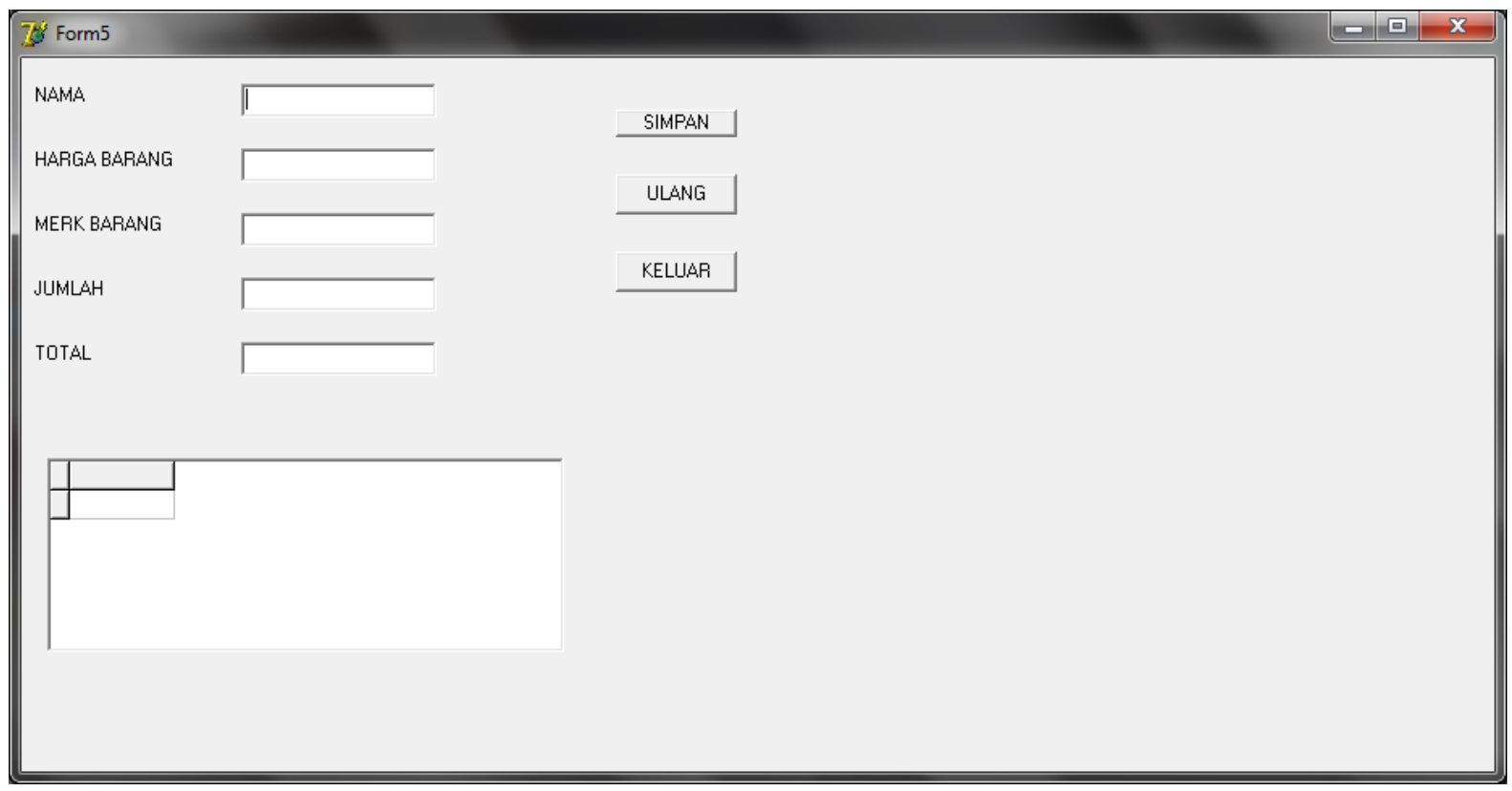




\section{B. PENJELASAN}

\section{- Kalkulator}

Aplikasi kalkulator merupakan alat bantu hitung elektronik yang banyak digunakan oleh semua orang. Bahkan di smartphone kita juga ada aplikasi kalkulator bukan? Fungsi kalkulator sangat bermanfaat bagi sebagian orang yang berkecimpung di dunia pendidikan,ekonomi, bisnis, perbankan, dan segala sesuatu yang berhubungan dengan uang. Di dalam kalkulator terdapat tombol kalkulasi seperti penjumlahan (+), pengurangan (-), perkalian (x), pembagian (:), dan operasi sederhana lainnya mungkin sudah banyak yang kalian ketahui serta bisa mengoperasikannya.

\section{- Segitiga}

Aplikasi menghitung segitiga merupakan salah satu alat bantu bagi sebagian siswa dalam mengerjakan tugas matematika di sekolahnya. Dengan adanya aplikasi ini siswa jadi tidak perlu menulis rumus yang cukup panjang utuk mendapatkan hasilnya. Cara mencari hasil segitiga terdapat rumus luas $1 / 2$ *Alas* Tinggi. Aplikasi ini dibuat menggunakan

\section{DISKUSI}

Berdasarkan penjelasan sebelumnya saya mencoba menerapkan pada lingkungan sekitar dan ternyata aplikasi yang saya buat sangat menolong mereka dalam mengefisienkan waktu untuk menghitung. delphi 7.0 dengan memasukan rumus segitiga sehingga membuat si pemakai cukup mengetik apa yang dia cari.

\section{- Diskon}

Aplikasi menghitung diskon sangat membantu bagi sebagian orang yang gemar berbelanja. Dengan adanya aplikasi ini kita tidak perlu lagi susah payah menghitung harga yang di diskon, cukup menulis nama barang beserta merk dan harga kemudian anda tinggal mengkilik pilihan diskonnya seperti $5 \%$ atau $10 \%$ kemudian anda akan melihat hasilnya.

\section{- Database}

Aplikasi database erupakan sekumpulan data yang sudah disusun sedemikan rupa dengan ketentuan atau aturan tertentu yang saling berelasi sehingga memudahkan pengguna dalam mengelolanya juga memudahkan memperoleh informasi. Selain itu adapula yang mendefinisikan database sebagai kumpulan file, tabel, atau arsip yang saling terhubung yang disimpan dalam media elektronik.

Tetapi dengan adanya aplikasi ini juga sebagain dari mereka menjadi malas untuk mencari secara manual. Selain itu juga mereka masih binggung apa itu database dan untuk apa kegunaannya. 


\section{REFRENSI}

[1]

A. S. Putra And O. M. Febriani,

"Knowledge Management Online Application In Pdam Lampung Province," In Prosiding International Conference On Information Technology And Business (Icitb), 2018, Pp. 181-187.

[2]

A. S. Putra, O. M. Febriani, And B. Bachry, "Implementasi Genetic Fuzzy System Untuk Mengidentifikasi Hasil Curian Kendaraan Bermotor Di Polda Lampung," J. Sist. Inf. Dan Manaj. Basis Data, Vol. 1, No.1, Pp. 21-30, 2018.
[3]

O. M. Febriani And A. S. Putra, "Sistem Informasi Monitoring Inventori Barang Pada Balai Riset Standardisasi Industri Bandar Lampung," J. Inform., Vol. 13, No. 1, Pp. 90-98, 2014.

[4] Putra, Arie Setya. "2018 Artikel Struktur Data, Audit Dan Jaringan Komputer." (2018).

[5]

Putra, A. S. (2018, July 17). Paperplain Fundamental Create Application With Borland Delphi 7.0 University Of Mitra Indonesia. Retrieved From Osf.Io/Pbrn9. 